\title{
Review Article \\ Targeted Therapy for HM1.24 (CD317) on Multiple Myeloma Cells
}

\author{
Takeshi Harada ${ }^{1}$ and Shuji Ozaki ${ }^{2}$ \\ ${ }^{1}$ Department of Medicine and Bioregulatory Sciences, University of Tokushima Graduate School of Medical Sciences, \\ 3-18-15 Kuramoto, Tokushima 770-8503, Japan \\ ${ }^{2}$ Department of Hematology, Tokushima Prefectural Central Hospital, 1-10-3 Kuramoto, Tokushima 770-8539, Japan
}

Correspondence should be addressed to Shuji Ozaki; ozaki@tph.gr.jp

Received 15 March 2014; Accepted 2 July 2014; Published 17 July 2014

Academic Editor: Marie-Christine Kyrtsonis

Copyright (C) 2014 T. Harada and S. Ozaki. This is an open access article distributed under the Creative Commons Attribution License, which permits unrestricted use, distribution, and reproduction in any medium, provided the original work is properly cited.

Multiple myeloma (MM) still remains an incurable disease, at least because of the existence of cell-adhesion mediated drugresistant MM cells and/or continuous recruitment of presumed MM cancer stem cell-like cells (CSCs). As a new alternative treatment modality, immunological approaches using monoclonal antibodies (mAbs) and/or cytotoxic T lymphocytes (CTLs) are now attracting much attention as a novel strategy attacking MM cells. We have identified that HM1.24 [also known as bone marrow stromal cell antigen 2 (BST2) or CD317] is overexpressed on not only mature MM cells but also MM CSCs. We then have developed a humanized mAb to HM1.24 and defucosylated version of the mAb to adapt to clinical practice. Moreover, we have successfully induced HM1.24-specific CTLs against MM cells. The combination of these innovative therapeutic modalities may likely exert an anti-MM activity by evading the drug resistance mechanism and eliminating presumed CSCs in MM.

\section{Introduction}

Multiple myeloma (MM) is a plasma cell neoplasm in the bone marrow and is likely to present with hypercalcemia, renal failure, anemia, bone resorption (CRAB), and/or immunodeficiency [1]. Treatment approaches in the management of MM have made a remarkable progress in the recent decades and are comprised of high-dose chemotherapy (melphalan) followed by autologous peripheral blood stem cell transplantation (PBSCT) and novel therapies using proteasome inhibitors and immunomodulatory drugs (IMiDs) [2, 3]. These strategies have improved overall survival of MM patients. However, most patients eventually relapse even after the achievement of complete response [4]. Therefore, other novel therapeutic approaches are strongly needed to further improve the outcome of MM.

Treatment with monoclonal antibody (mAb) has demonstrated the efficacy in several hematological malignancies such as CD20-positive malignant lymphomas and chronic lymphocytic leukemia $[5,6]$. The principal mechanisms of its cytotoxic activity are derived from antibody-dependent cellmediated cytotoxicity (ADCC) and complement-dependent cytotoxicity (CDC) [7]. ADCC is induced when mAb binds to the specific antigen on the surface of malignant cells followed by binding of the $\mathrm{Fc}$ domain of the $\mathrm{mAb}$ to the $\mathrm{Fc}$ receptors on the surface of effector cells. The binding affinity between the Fc domains and the Fc receptors is related to control of fucosylation of $\mathrm{N}$-linked oligosaccharides within the immunoglobulin heavy chain Fc regions $[8,9]$. To enhance the binding affinity of $\mathrm{mAbs}$ to $\mathrm{Fc}$ receptors, defucosylated versions of the $\mathrm{mAbs}$ have been developed [9].

In $\mathrm{MM}$, several mAbs with confirmed cytotoxic activity have been developed over the past years [10-12]. The targeted molecules of the mAbs include CS1 [13, 14], CD38 [15], CD138 [16], and CD40 [17]. We have identified a new plasma cellspecific antigen, HM1.24, and developed a humanized antiHM1.24 mAb (AHM). To enhance the cytotoxic activity of the AHM, we have developed a defucosylated version of the AHM and antibody-drug conjugates (ADC).

In addition, to explore the relevance of cellular immunity against HM1.24, we have investigated the activity of HM1.24 
peptide-specific cytotoxic T lymphocytes (CTLs) by using peripheral blood mononuclear cells (PBMCs) and peripheral blood stem cells (PBSC) harvested from MM patients.

In this review, we summarize the targeted therapies for HM1.24 and discuss the perspectives of these new targeted therapies in MM.

\section{HM1.24 Antigen (CD317)}

HM1.24 was originally identified as a cell-surface protein that is preferentially overexpressed on MM cells [18]. Later, this protein was found to be identical to bone marrow stromal cell antigen 2 (BST2) and was designated as CD317 [19-22]. This antigen is a type II transmembrane glycoprotein consisting of 180 amino acids with a molecular weight of 29 to $33 \mathrm{kD}$ and is expressed as a homodimer by the disulfide bond (Figure 1). Regarding the topology of HM1.24, the N-terminus is located in the cytoplasm and the transmembrane domain is present near the N-terminus [23]. The cytoplasmic domain contains a Tyr-(X)-Tyr- $(\mathrm{X})_{3}$-Pro-Met sequence motif, which is conserved in mouse, rhesus, and human. The extracellular domain bears two N-linked glycosylation sites, and the Cterminus is modified with a glycosylphosphatidylinositol (GPI) membrane anchor. In addition, HM1.24 is a lipid raftassociated glycoprotein traversing between the cell surface and the Golgi apparatus [23-25].

The HM1.24 gene is located on chromosome 19p13.2 [19]. The promoter region of HM1.24 gene contains the interferon(IFN-) stimulated response elements such as IFN related factor (IRF)-1/2 and IFN-stimulated gene factor (ISGF) 3 , and therefore, the expression of HM1.24 can be upregulated by IFNs especially IFN $-\alpha[20,26]$.

The expression of HM1.24 mRNA is upregulated on both normal and neoplastic plasma cells, and the expression level is increased in symptomatic MM when compared with monoclonal gammopathy of undetermined significance (MGUS) or smoldering MM [27] (http://amazonia.transcriptome.eu/ expression.php?geneId=Hs.118110\&zone=Hematology-MM). Although the mRNA expression levels vary among primary MM cells [28-30] (http://amazonia.transcriptome.eu/ expression.php?geneId=Hs.118110\&zone $=$ Hematology-MM), more than $1 \times 10^{4}$ molecules/cell of HM1.24 are detected at the surface of MM cells in more than $85 \%$ of patients [31].

During the normal plasma cell differentiation, HM1.24 mRNA is expressed at the highest level in plasmablasts as well as in early plasma cells compared with mature plasma cells [30, 32] (http://amazonia.transcriptome.eu/ expression.php?geneId=Hs.118110\&zone=PlasmaCell). These findings support the idea that HM1.24 is an intriguing target molecule for immature MM cells or MM cancer stem cells. In fact, we have observed that side population (SP) of MM cells including MM cancer stem cell-like cells (CSCs) expressed HM1.24 at high levels [33].

Several studies have shown that HM1.24 is also expressed on a variety of human tissues and organs such as hepatocytes, pneumocytes, salivary glands, kidney, and vascular endothelium both at the mRNA and protein levels $[19,21$, 34]. However, the expression profiles at the protein level in

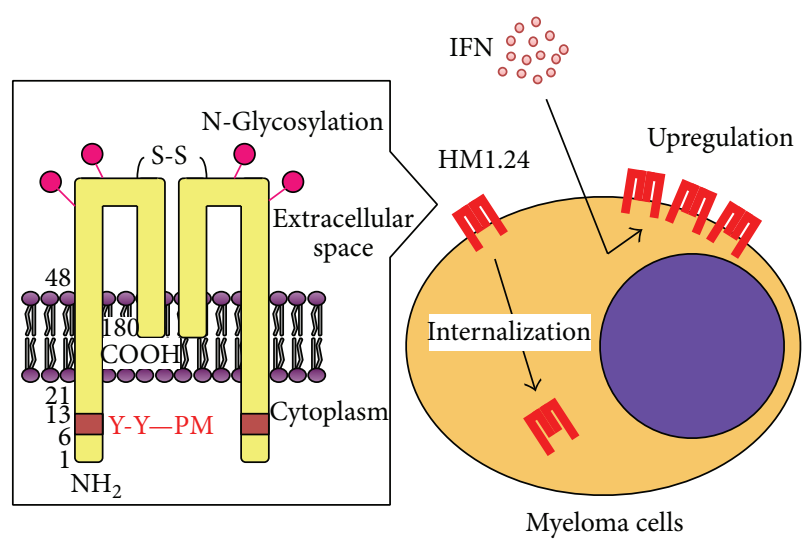

FIGURE 1: The schema of the structure of HM1.24. HM1.24 is a type II transmembrane glycoprotein that is selectively overexpressed on MM cells as a homodimer with a unique topology. HM1.24 internalizes and localizes to the Golgi apparatus. In the promoter region of HM1.24, there are several cis-elements for transcription factors such as IRF-1/2 and ISGF3, and the expression levels of HM1.24 can be upregulated by IFN.

normal tissues have not been clarified yet. In addition, we and other researchers have found that HM1.24 is overexpressed on various cancer cells isolated from breast, lung, kidney, endometrium, and skin [26, 35-43].

The physiological role of HM1.24 remains unclarified; however, recent studies have shown that HM1.24 directly binds to immunoglobulin-like transcript 7 (ILT7) protein and initiates signaling via the ILT-7-FceRI $\gamma$ complex $[44,45]$. HM1.24 is now termed "tetherin" as a molecule that tethers outgoing virions to the infected cell surface preventing their dissemination [46-48]. However, its biological role in MM cells has not been clarified yet.

\section{The Development of Anti-HM1.24 mAb Therapy}

3.1. Mouse Anti-HM1.24 mAb. We first developed a mouse anti-HM1.24 mAb (IgG2a- $\kappa$ ) by immunizing Balb/c mice with human MM cells [18]. After fusing spleen cells collected from the immunized mice with myeloma cells and cloning of these fused cells, mAbs that react with the cell surface antigens were obtained after screening the hybridomas by flow cytometry.

To evaluate the specificity of the mouse anti-HM1.24 mAb in vivo, we employed a mouse xenograft model using severe combined immunodeficiency (SCID) mice. After establishing subcutaneous tumors of human plasmacytoma (RPMI 8226 cells) in SCID mice, the radiolabeled mouse antiHM1.24 mAb was injected intravenously, and the biodistribution of the $\mathrm{mAb}$ was studied $[49,50]$. Our results have shown that the mouse anti-HM1.24 mAb selectively accumulates in the xenograft tumors, suggesting that the anti-HM1.24 mAb has a sufficient specificity for targeting human MM cells in vivo. 
We next studied the antitumor activity of the mouse antiHM1.24 mAb. Our in vitro experiments have shown that the mouse anti-HM1.24 mAb induces ADCC in the presence of effector cells obtained from mice spleen and CDC in the presence of baby rabbit serum [51]. We next evaluated the in vivo efficacy of the mouse anti-HM1.24 mAb using human myeloma xenograft models in SCID mice [51]. The treatment with the mouse anti-HM1.24 mAb has resulted in a decrease of the serum levels of M-proteins and the size of the tumors and has resulted in not only a prolonged survival of the mice but also a cure in some of them.

3.2. Humanized Anti-HM1.24 mAb (AHM). Because the mouse anti-HM1.24 mAb exerted a marked anti-MM activity through the operation of ADCC and CDC machineries, we have established a humanized anti-HM1.24 mAb (AHM, IgG1- $\kappa$ ) by grafting the complementary-determining regions $[52,53]$. AHM induced ADCC in the presence of human PBMCs against both MM cell lines and MM cells from MM patients, but not CDC in spite of the presence of human serum [31, 52]. The ADCC activity of AHM was increased in a dose-, an effector to target $(\mathrm{E} / \mathrm{T})$ ratio-, and HM1.24 expression-dependent fashion. In addition, our in vivo experiments have shown that AHM kills MM cells through ADCC [54].

Based on these results, the safety and efficacy of AHM were investigated in a phase I/II clinical study in patients with relapsed or refractory MM in the UK. [55]. Although adverse events were very modest and manageable, the response rate was relatively low in the study. This was considered probably due to the diminished activity of effector cells in this heavily pretreated patient population.

3.3. Defucosylated Versions of AHM. In the context of ADCC activity, it has been shown that physiological levels of human serum IgG strongly inhibit the ADCC activity of therapeutic antibodies administered [56]. In addition, a genetic polymorphism of $\mathrm{Fc} \gamma$ receptor $(\mathrm{Fc} \gamma \mathrm{R})$ IIIa influences the binding affinity between $\mathrm{Fc}$ domains of $\mathrm{mAb}$ and $\mathrm{F} c \gamma$ RIIIa of effector cells [57-59]. The polymorphism of Fc $\gamma$ RIIIa is present on position 158 [valine $(\mathrm{V})$ or phenylalanine $(\mathrm{F})$ ], and patients with homozygous $158 \mathrm{~F} / \mathrm{F}$ or heterozygous $158 \mathrm{~V} / \mathrm{F}$ alleles of Fc $\gamma$ RIIIa have been shown to have a lower response rate to rituximab treatment $[58,59]$. On the other hand, the binding affinity between the two is controlled by fucosylation in $\mathrm{N}$-linked oligosaccharides within immunoglobulin heavy chain Fc regions $[8,9]$. Therefore, defucosylated mAbs might overcome the impaired ADCC activity in terms of a low E/T ratio and a low Fc $\gamma$ RIIIa affinity. To overcome cellular immune deficiency in MM, we have established a defucosylated version of AHM (YB-AHM) with a higher binding ability to Fc $\gamma$ RIIIa [60]. We have found that YB-AHM elicits ADCC more effectively than the parental AHM even with low $\mathrm{E} / \mathrm{T}$ ratios. Similarly, Tai et al. have shown that Fc-engineered AHM with two amino acid substitutions (S239D/I332E) in the IgG1 Fc portion strongly induces anti-MM activity in vitro and in vivo [61].

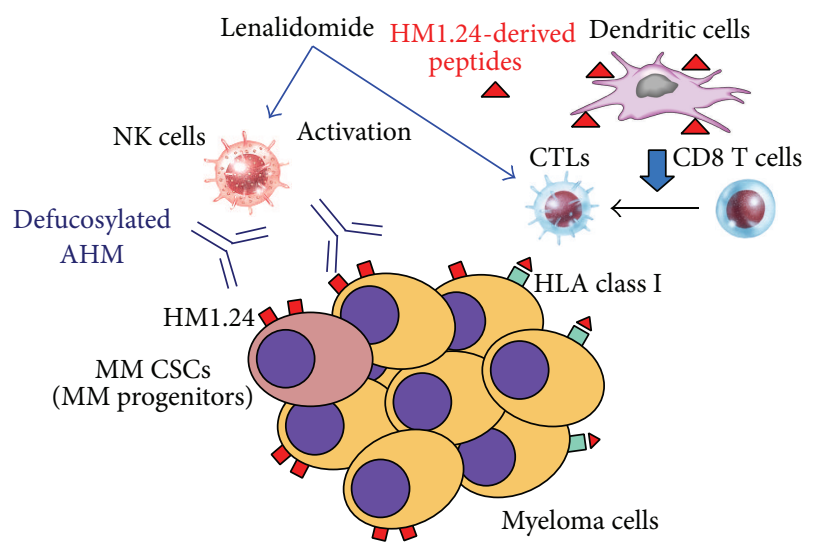

FIGURE 2: HM1.24-targeted therapy with mAbs and CTLs. Defucosylated AHM induces ADCC activity against MM cells including cancer stem cell-like cells (CSCs) in the presence of human effector cells such as NK cells. On the other hand, functional dendritic cells and HM1.24 peptide-specific CTLs can be induced from PBMCs or PBSC harvests, and these CTLs have the cytotoxic activity against MM cells. Len augments the activity of these cellular immunities.

\section{Augmentation of ADCC Activity by Lenalidomide (Len)}

Len, one of the IMiDs, induces not only direct cytotoxic effects on MM cells but also immunomodulatory, antiinflammatory, and antiangiogenic effects on the cells surrounding and supporting MM cells in the bone marrow [62]. In particular, Len stimulates the activity of T, NKT, and NK cells and enhances the ADCC activity (Figure 2). For these reasons, Len has been combined with various $m A b s$ including anti-CS1 [63, 64], anti-CD38 [65], and anti-CD20 [66] to enhance the therapeutic efficacy of them.

Tai et al. and our group severally studied the ADCC activity of Fc-engineered AHM or YB-AHM in combination with Len against $\mathrm{MM}$ cell lines and MM cells obtained from bone marrow mononuclear cells of MM patients [61, 67]. The results have shown that Len can enhance the ADCC activity of both defucosylated versions of AHM and Fc-engineered AHM.

MM cancer stem cell-like cells (CSCs) have been proposed as responsible for drug resistance and relapse although they are not properly defined yet [68]. Side population (SP) cells have been identified as a drug resistant fraction that contains CSCs in MM [33]. We have found that HM1.24 is highly expressed on the surface of SP cells and that the combination of YB-AHM plus Len effectively reduces the number of SP fractions in MM cell lines [67]. Furthermore, this combination inhibited the clonogenic potential of MM CSCs in vitro [67]. Thus, the combination therapy with YBAHM plus Len might become an effective strategy to target putative MM CSCs (Figure 2).

With respect to targeting therapy, the number and function of effector cells are important for eliciting ADCC activity. Therefore, YB-AHM therapy could be a suitable strategy as consolidation and/or maintenance therapy because MM cells have already been reduced in number and the number of 


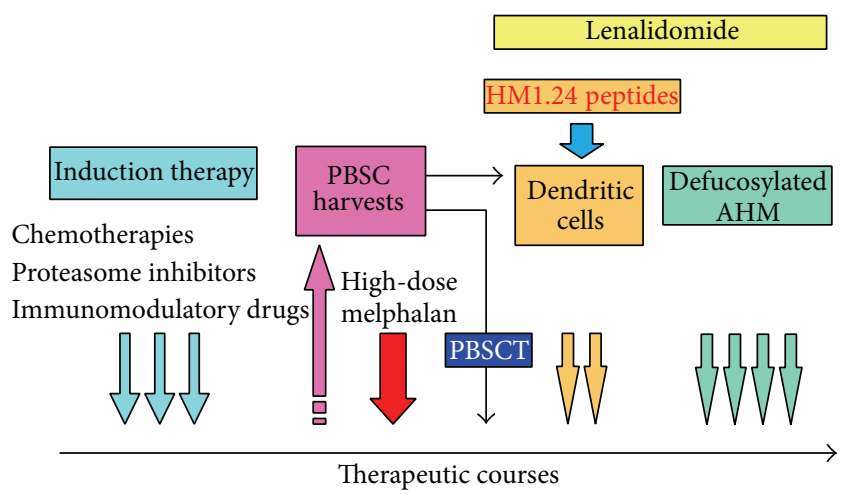

FIgURE 3: The combination strategy with HM1.24-targeted therapies and the current therapeutic regimen in MM. Induction therapy containing proteasome inhibitors and/or IMiDs and consolidation therapy with high-dose chemotherapy followed by autologous PBSCT induce favorable therapeutic effects; however, the existence of minimal residual disease or MM CSCs is related to relapse and refractoriness. To overcome the drug resistance of MM cells, active immunotherapy with HM1.24-derived peptides and dendritic cells from autologous PBSC harvests and passive immunotherapy with defucosylated AHM might be effective approaches along with lenalidomide in the treatment of MM.

effector cells has recovered (relatively high $\mathrm{E} / \mathrm{T}$ ratio) by this phase (Figure 3).

\section{HM1.24 mAb-Conjugated ADC}

ADC is another approach to enhance the efficacy of $\mathrm{mAb}$ therapy. Several ADCs have been developed by the conjugation of $\mathrm{mAb}$ with either cytotoxins or radiation emitters to increase the antitumor effect. HM1.24 is a suitable element of ADC because this antigen is internalized from MM cell surface into the Golgi apparatus. Therefore, we have manufactured ADC by using an internalizing mAbs specific to HM1.24 [69]. One of the fully human antiHM1.24 mAbs, b-76-8, is rapidly internalized after cell surface binding. Thus, ADC consisted of b-76-8 and the analog of the cytotoxic drug maytansine, DM1 [ $\mathrm{N}^{\prime}$-deacetyl- $2^{\prime}$ (3-mercapto-1-oxopropyl)-maytansine], has been developed. Our results have shown that this ADC significantly elicits the cytotoxic activity against MM cells without effector cells in vitro and in vivo. Recently, Staudinger et al. have established a novel single-chain immunotoxin, HM1.24-ETA', by genetic fusion of a HM1.24-specific single chain Fv antibody and a truncated variant of Pseudomonas aeruginosa exotoxin A $\left(\mathrm{ETA}^{\prime}\right)[70]$.

\section{HM1.24 Peptide-Specific CTLs}

Besides anti-HM1.24 mAb therapy, we have also examined the possibility of HM1.24-specific CTL therapy against MM cells (Figure 2). We selected four HM1.24-derived peptides that possess binding motifs for HLA-A2 or HLA-A24 by using two computer-based algorithms and developed the methods inducing HM1.24 peptide-specific CTLs from PBMCs of healthy donors or PBSC harvests from MM patients in the presence of HM1.24 peptide-pulsed dendritic cells [71]. The experiments in vitro have shown that HM1.24 peptideinduced CTLs have the direct cytotoxic activity against MM cells. Several investigators have reported similar results by using HM1.24-derived peptides [72, 73].

Notably, Len has been reported to augment the cytotoxic activity of CTLs in MM [74] including HM1.24-specific CTLs [75]. On the other hand, Herth et al. have recently reported that thalidomide maintenance therapy compromises the HM1.24-specific CTL immunity in MM patients who underwent PBSCT [76]. These results indicate that the cellular immunotherapy targeted for HM1.24 could also be effective in $M M$, and further studies are warranted to determine whether the IMiDs maintenance therapy with Len or pomalidomide could augment antigen-specific $\mathrm{T}$ cell activity.

High-dose chemotherapy followed by autologous PBSCT is considered the most effective consolidation therapy for younger patients with MM. For this procedure, PBSCs are harvested and cryopreserved together with peripheral lymphocytes and monocytes. Therefore, we have investigated the possibility for active CTL therapy by using residual PBSC products after PBSCT. Tarte et al. have previously reported the generation of functional dendritic cells using apheresis products from MM patients [77]. Our results have confirmed that frozen PBSC harvests are useful source for dendritic cells and also for HM1.24-specific CTLs [71]. Thus, we consider that HM1.24-specific cellular immunotherapy could be applied to increase the therapeutic efficacy of autologous PBSCT (Figure 3).

\section{Conclusion}

HM1.24 is an overexpressed antigen on MM cells, and HM1.24-targeted therapies might provide alternative strategies in the management of MM. With regard to mAb therapy, the defucosylated versions of AHM have been established and the synergistic effects have been shown when combined with Len. To further enhance the cytotoxic activity of mAbs, several types of ADC have been developed. Moreover, CTLs specific for HM1.24 have been successfully induced from PBSC harvests obtained from MM patients, and the activity could further be augmented by Len. Most importantly, in vitro experiments have shown that some of these approaches are effective for the eradication of MM CSCs.

The treatment paradigm of MM has been dramatically changed since the introduction of autologous PBSCT and novel agents such as thalidomide, lenalidomide, and bortezomib. HM1.24-targeted therapies can be combined with the current therapeutic approaches (Figure 3). Further studies are needed to determine whether these strategies could improve the outcome of MM patients.

\section{Conflict of Interests}

The authors declare no competing financial interests related to this work. 


\section{Acknowledgments}

This work was supported in part by Grants-in-Aid for Scientific Research (C) for Shuji Ozaki from the Ministry of Education, Culture, Sports, Science and Technology of Japan. The authors thank Dr. Tetsuya Goto for his pioneering work in establishing the anti-HM1.24 mAb and for his continued support for our research projects. They also thank Dr. Kazuyuki Shimizu for his thorough review of the paper.

\section{References}

[1] R. A. Kyle, J. A. Child, K. Anderson et al., "Criteria for the classification of monoclonal gammopathies, multiple myeloma and related disorders: a report of the International Myeloma Working Group," British Journal of Haematology, vol. 121, no. 5, pp. 749-757, 2003.

[2] S. K. Kumar, S. V. Rajkumar, A. Dispenzieri et al., "Improved survival in multiple myeloma and the impact of novel therapies," Blood, vol. 111, no. 5, pp. 2516-2520, 2008.

[3] F. Gay, A. Larocca, P. Wijermans et al., "Complete response correlates with long-term progression-free and overall survival in elderly myeloma treated with novel agents: Analysis of 1175 patients," Blood, vol. 117, no. 11, pp. 3025-3031, 2011.

[4] A. Palumbo and K. Anderson, "Multiple myeloma," The New England Journal of Medicine, vol. 364, no. 11, pp. 1046-1060, 2011.

[5] D. G. Maloney, "Anti-CD20 antibody therapy for B-cell lymphomas," The New England Journal of Medicine, vol. 366, no. 21, pp. 2008-2016, 2012.

[6] I. Tazi, H. Nafil, and L. Mahmal, "Monoclonal antibodies in hematological malignancies: Past, present and future," Journal of Cancer Research and Therapeutics, vol. 7, no. 4, pp. 399-407, 2011.

[7] M. X. Sliwkowski and I. Mellman, "Antibody therapeutics in cancer," Science, vol. 341, no. 6151, pp. 1192-1198, 2013.

[8] R. L. Shields, J. Lai, R. Keck et al., "Lack of fucose on human IgG1 N-linked oligosaccharide improves binding to human Fc $\gamma$ RIII and antibody-dependent cellular toxicity," The Journal of Biological Chemistry, vol. 277, no. 30, pp. 26733-26740, 2002.

[9] T. Shinkawa, K. Nakamura, N. Yamane et al., "The absence of fucose but not the presence of galactose or bisecting $\mathrm{N}$ acetylglucosamine of human IgG1 complex-type oligosaccharides shows the critical role of enhancing antibody-dependent cellular cytotoxicity," The Journal of Biological Chemistry, vol. 278, no. 5, pp. 3466-3473, 2003.

[10] J. Yang and Q. Yi, “Therapeutic monoclonal antibodies for multiple myeloma: an update and future perspectives," The American Journal of Blood Research, vol. 1, no. 1, pp. 22-33, 2011.

[11] E. M. Ocio, P. G. Richardson, S. V. Rajkumar et al., "New drugs and novel mechanisms of action in multiple myeloma in 2013: a report from the International Myeloma Working Group (IMWG)," Leukemia, vol. 28, no. 3, pp. 525-242, 2014.

[12] N. W. C. J. van de Donk, S. Kamps, T. Mutis, and H. M. Lokhorst, "Monoclonal antibody-based therapy as a new treatment strategy in multiple myeloma," Leukemia, vol. 26, no. 2, pp. 199-213, 2012.

[13] E. D. Hsi, R. Steinle, B. Balasa et al., "CS1, a potential new therapeutic antibody target for the treatment of multiple myeloma," Clinical Cancer Research, vol. 14, no. 9, pp. 2775-2784, 2008.

[14] Y. Tai, M. Dillon, W. Song et al., "Anti-CSl humanized monoclonal antibody HuLuc63 inhibits myeloma cell adhesion and induces antibody-dependent cellular cytotoxicity in the bone marrow milieu," Blood, vol. 112, no. 4, pp. 1329-1337, 2008.

[15] M. de Weers, Y. Tai, M. S. van der Veer et al., "Daratumumab, a novel therapeutic human CD38 monoclonal antibody, induces killing of multiple myeloma and other hematological tumors," Journal of Immunology, vol. 186, no. 3, pp. 1840-1848, 2011.

[16] H. Ikeda, T. Hideshima, M. Fulciniti et al., "The monoclonal antibody nBT062 conjugated to cytotoxic maytansinoids has selective cytotoxicity against CD138-positive multiple myeloma cells in vitro and in vivo," Clinical Cancer Research, vol. 15, no. 12, pp. 4028-4037, 2009.

[17] Y. Tai, X. Li, X. Tong et al., "Human anti-CD40 antagonist antibody triggers significant antitumor activity against human multiple myeloma," Cancer Research, vol. 65, no. 13, pp. 58985906, 2005.

[18] T. Goto, S. J. Kennel, M. Abe et al., "A novel membrane antigen selectively expressed on terminally differentiated human B cells," Blood, vol. 84, no. 6, pp. 1922-1930, 1994.

[19] J. Ishikawa, T. Kaisho, H. Tomizawa et al., "Molecular cloning and chromosomal mapping of a bone marrow stromal cell surface gene, BST2, that may be involved in pre-B-cell growth," Genomics, vol. 26, no. 3, pp. 527-534, 1995.

[20] T. Ohtomo, Y. Sugamata, Y. Ozaki et al., "Molecular cloning and characterization of a surface antigen preferentially overexpressed on multiple myeloma cells," Biochemical and Biophysical Research Communications, vol. 258, no. 3, pp. 583-591, 1999.

[21] M. Vidal-Laliena, X. Romero, S. March, V. Requena, J. Petriz, and P. Engel, "Characterization of antibodies submitted to the B cell section of the 8th human leukocyte differentiation antigens workshop by flow cytometry and immunohistochemistry," Cellular Immunology, vol. 236, no. 1-2, pp. 6-16, 2005.

[22] H. Zola, B. Swart, I. Nicholson et al., "CD molecules 2005: human cell differentiation molecules," Blood, vol. 106, no. 9, pp. 3123-3126, 2005.

[23] S. Kupzig, V. Korolchuk, R. Rollason, A. Sugden, A. Wilde, and G. Banting, "Bst-2/HM1.24 is a raft-associated apical membrane protein with an unusual topology," Traffic, vol. 4, no. 10, pp. 694709, 2003.

[24] N. Masuyama, T. Kuronita, R. Tanaka et al., "HM1.24 is internalized from lipid rafts by Clathrin-mediated endocytosis through interaction with $\alpha$-adaptin," The Journal of Biological Chemistry, vol. 284, no. 23, pp. 15927-15941, 2009.

[25] J. Amano, N. Masuyama, Y. Hirota et al., "Antigen-dependent internalization is related to rapid elimination from plasma of humanized anti-HM1.24 monoclonal antibody," Drug Metabolism and Disposition, vol. 38, no. 12, pp. 2339-2346, 2010.

[26] S. Kawai, Y. Azuma, E. Fujii et al., "Interferon- $\alpha$ enhances CD317 expression and the antitumor activity of anti-CD317 monoclonal antibody in renal cell carcinoma xenograft models," Cancer Science, vol. 99, no. 12, pp. 2461-2466, 2008.

[27] F. Zhan, Y. Huang, S. Colla et al., "The molecular classification of multiple myeloma," Blood, vol. 108, no. 6, pp. 2020-2028, 2006.

[28] S. Assou, D. Cerecedo, S. Tondeur et al., "A gene expression signature shared by human mature oocytes and embryonic stem cells," BMC Genomics, vol. 10, article 10, 2009.

[29] J. Corre, K. Mahtouk, M. Attal et al., "Bone marrow mesenchymal stem cells are abnormal in multiple myeloma," Leukemia, vol. 21, no. 5, pp. 1079-1088, 2007.

[30] M. Jourdan, A. Caraux, J. de Vos et al., "An in vitro model of differentiation of memory B cells into plasmablasts and plasma 
cells including detailed phenotypic and molecular characterization," Blood, vol. 114, no. 25, pp. 5173-5181, 2009.

[31] S. Kawai, Y. Koishihara, S. Iida et al., "Construction of a conventional non-radioisotope method to quantify HM1.24 antigens: Correlation of HM1.24 levels and ADCC activity of the humanized antibody against HM1.24," Leukemia Research, vol. 30, no. 8, pp. 949-956, 2006.

[32] M. Jourdan, A. Caraux, G. Caron et al., "Characterization of a transitional preplasmablast population in the process of human B cell to plasma cell differentiation," Journal of Immunology, vol. 187, no. 8, pp. 3931-3941, 2011.

[33] A. Ikegame, S. Ozaki, D. Tsuji et al., "Small molecule antibody targeting HLA class i inhibits myeloma cancer stem cells by repressing pluripotency-associated transcription factors," Leukemia, vol. 26, no. 9, pp. 2124-2134, 2012.

[34] E. Erikson, T. Adam, S. Schmidt et al., "In vivo expression profile of the antiviral restriction factor and tumor-targeting antigen CD317/BST-2/HM1.24/tetherin in humans," Proceedings of the National Academy of Sciences of the United States of America, vol. 108, no. 33, pp. 13688-13693, 2011.

[35] J. Walter-Yohrling, X. Cao, M. Callahan et al., "Identification of genes expressed in malignant cells that promote invasion," Cancer Research, vol. 63, no. 24, pp. 8939-8947, 2003.

[36] M. Becker, A. Sommer, J. R. Krätzschmar, H. Seidel, H. Pohlenz, and I. Fichtner, "Distinct gene expression patterns in a tomoxifen-sensitive human mammary carcinoma xenograft and its tamoxifen-resistant subline MaCa 3366/TAM," Molecular Cancer Therapeutics, vol. 4, no. 1, pp. 151-168, 2005.

[37] D. Cai, J. Cao, Z. Li et al., "Up-regulation of bone marrow stromal protein 2 (BST2) in breast cancer with bone metastasis," BMC Cancer, vol. 9, article 102, 2009.

[38] W. Wang, Y. Nishioka, S. Ozaki et al., "HM1.24 (CD317) is a novel target against lung cancer for immunotherapy using antiHM1.24 antibody," Cancer Immunology, Immunotherapy, vol. 58, no. 6, pp. 967-976, 2009.

[39] W. Wang, Y. Nishioka, S. Ozaki et al., "Chimeric and humanized anti-HM1.24 antibodies mediate antibody-dependent cellular cytotoxicity against lung cancer cells," Lung Cancer, vol. 63, no. 1, pp. 23-31, 2009.

[40] A. Sayeed, G. Luciani-Torres, Z. Meng, J. L. Bennington, D. H. Moore, and S. H. Dairkee, "Aberrant regulation of the BST2 (Tetherin) promoter enhances cell proliferation and apoptosis evasion in high grade breast cancer cells," PLoS ONE, vol. 8, no. 6, Article ID e67191, 2013.

[41] E. H. Yi, H. Yoo, K. H. Noh et al., "BST-2 is a potential activator of invasion and migration in tamoxifen-resistant breast cancer cells," Biochemical and Biophysical Research Communications, vol. 435, no. 4, pp. 685-690, 2013.

[42] T. Yokoyama, T. Enomoto, S. Serada et al., "Plasma membrane proteomics identifies bone marrow stromal antigen 2 as a potential therapeutic target in endometrial cancer," International Journal of Cancer, vol. 132, no. 2, pp. 472-484, 2013.

[43] Y. F. Wong, T. H. Cheung, K. W. K. Lo et al., "Identification of molecular markers and signaling pathway in endometrial cancer in Hong Kong Chinese women by genome-wide gene expression profiling," Oncogene, vol. 26, no. 13, pp. 1971-1982, 2007.

[44] W. Cao, L. Bover, M. Cho et al., "Regulation of TLR7/9 responses in plasmacytoid dendritic cells by BST2 and ILT7 receptor interaction," Journal of Experimental Medicine, vol. 206, no. 7, pp. 1603-1614, 2009.
[45] W. Cao and L. Bover, "Signaling and ligand interaction of ILT7: receptor-mediated regulatory mechanisms for plasmacytoid dendritic cells," Immunological Reviews, vol. 234, no. 1, pp. 163$176,2010$.

[46] S. J. D. Neil, T. Zang, and P. D. Bieniasz, “Tetherin inhibits retrovirus release and is antagonized by HIV-1 Vpu," Nature, vol. 451, no. 7177, pp. 425-430, 2008.

[47] J. Martin-Serrano and S. J. D. Neil, "Host factors involved in retroviral budding and release," Nature Reviews Microbiology, vol. 9, no. 7, pp. 519-531, 2011.

[48] D. T. Evans, R. Serra-Moreno, R. K. Singh, and J. C. Guatelli, "BST-2/tetherin: a new component of the innate immune response to enveloped viruses," Trends in Microbiology, vol. 18, no. 9, pp. 388-396, 2010.

[49] K. Ozaki, S. Ozaki, M. Kosaka, and S. Saito, "Localization and imaging of human plasmacytoma xenografts in severe combined immunodeficiency mice by a new murine monoclonal antibody, anti-HM1.24.," The Tokushima journal of experimental medicine, vol. 43, no. 1-2, pp. 7-15, 1996.

[50] S. Ozaki, M. Kosaka, M. Harada, H. Nishitani, M. Odomi, and T. Matsumoto, "Radioimmunodetection of human myeloma xenografts with a monoclonal antibody directed against a plasma cell specific antigen, HM1.24," Cancer, vol. 82, no. 11, pp. 2184-2190, 1998.

[51] S. Ozaki, M. Kosaka, S. Wakatsuki, M. Abe, Y. Koishihara, and T. Matsumoto, "Immunotherapy of multiple myeloma with a monoclonal antibody directed against a plasma cell-specific antigen, HM1.24," Blood, vol. 90, no. 8, pp. 3179-3186, 1997.

[52] S. Ozaki, M. Kosaka, Y. Wakahara et al., "Humanized antiHM1.24 Antibody mediates myeloma cell cytotoxicity that is enhanced by cytokine stimulation of effector cells," Blood, vol. 93, no. 11, pp. 3922-3930, 1999.

[53] K. Ono, T. Ohtomo, K. Yoshida et al., "The humanized antiHM1.24 antibody effectively kills multiple myeloma cells by human effector cell-mediated cytotoxicity," Molecular Immunology, vol. 36, no. 6, pp. 387-395, 1999.

[54] S. Kawai, Y. Yoshimura, S. Iida et al., "Antitumor activity of humanized monoclonal antibody against HM1.24 antigen in human myeloma xenograft models," Oncology Reports, vol. 15, no. 2, pp. 361-367, 2006.

[55] R. Powles, B. Sirohi, and G. Morgan, "A phase I study of the safety, tolerance, pharmacokinetics, antigenicity and efficacy of a single intravenous dose of AHM followed by multiple doses of intravenous AHM in patients with multiple myeloma," Blood, vol. 98, no. 11, article 165a, 2001.

[56] S. Preithner, S. Elm, S. Lippold et al., "High concentrations of therapeutic IgG1 antibodies are needed to compensate for inhibition of antibody-dependent cellular cytotoxicity by excess endogenous immunoglobulin G," Molecular Immunology, vol. 43, no. 8, pp. 1183-1193, 2006.

[57] H. R. Koene, M. Kleijer, J. Algra, D. Roos, A. E. G. K. von dem Borne, and M. de Haas, "Fc $\gamma$ RIIIa-158V/F polymorphism influences the binding of IgG by natural killer cell FC $\gamma$ RIIIa, independently of the FC $\gamma$ RIIIa-48L/R/H phenotype," Blood, vol. 90, no. 3, pp. 1109-1114, 1997.

[58] G. Cartron, L. Dacheux, G. Salles et al., "Therapeutic activity of humanized anti-CD20 monoclonal antibody and polymorphism in IgG Fc receptor Fc $\gamma$ rIIIa gene," Blood, vol. 99, no. 3, pp. 754-758, 2002.

[59] W. Weng and R. Levy, "Two immunoglobulin G fragment $\mathrm{C}$ receptor polymorphisms independently predict response to 
rituximab in patients with follicular lymphoma," Journal of Clinical Oncology, vol. 21, no. 21, pp. 3940-3947, 2003.

[60] T. Ishiguro, S. Kawai, K. Habu et al., "A defucosylated antiCD317 antibody exhibited enhanced antibody-dependent cellular cytotoxicity against primary myeloma cells in the presence of effectors from patients," Cancer Science, vol. 101, no. 10, pp. 2227-2233, 2010.

[61] Y. Tai, H. M. Horton, S. Kong et al., "Potent in vitro and in vivo activity of an Fc-engineered humanized anti-HM1.24 antibody against multiple myeloma via augmented effector function," Blood, vol. 119, no. 9, pp. 2074-2082, 2012.

[62] H. Quach, D. Ritchie, A. K. Stewart et al., "Mechanism of action of immunomodulatory drugs (IMiDS) in multiple myeloma," Leukemia, vol. 24, no. 1, pp. 22-32, 2010.

[63] S. Lonial, R. Vij, J. L. Harousseau et al., "Elotuzumab in combination with lenalidomide and low-dose dexamethasone in relapsed or refractory multiple myeloma," Journal of Clinical Oncology, vol. 30, no. 16, pp. 1953-1959, 2012.

[64] P. G. Richardson, S. Jagannath, P. Moreau et al., “ A Phase 2 study of elotuzumab (Elo) in combination with lenalidomide and low-dose dexamethasone (Ld) in patients (pts) with relapsed/refractory multiple myeloma (R/R MM): updated results," in Proceedings of the ASH Annual Meeting Abstracts, 2012, abstract 202.

[65] M. S. van der Veer, M. de Weers, B. van Kessel et al., "Towards effective immunotherapy of myeloma enhanced elimination of myeloma cells by combination of lenalidomide with the human CD38 monoclonal antibody daratumumab," Haematologica, vol. 96, no. 2, pp. 284-290, 2011.

[66] G. S. Nowakowski, B. Laplant, T. M. Habermann et al., "Lenalidomide can be safely combined with R-CHOP (R2CHOP) in the initial chemotherapy for aggressive Bcell lymphomas: phase I study," Leukemia, vol. 25, no. 12, pp. 1877-1881, 2011.

[67] T. Harada, S. Ozaki, A. Oda et al., "Combination with a defucosylated anti-HM1.24 monoclonal antibody plus lenalidomide induces marked ADCC against myeloma cells and their progenitors," PLoS ONE, vol. 8, no. 12, Article ID e83905, 2013.

[68] M. Abe, T. Harada, and T. Matsumoto, "Concise review: defining and targeting myeloma stem cell-like cells," Stem Cells, vol. 32, no. 5, pp. 1067-1073, 2014.

[69] S. Ozaki, T. Tomura, E. Sekimoto et al., "Anti-myeloma activity of the maytansinoid immunoconjugate of internalizing human monoclonal antibody specific for HM1.24/BST2 (CD317)," ASH Annual Meeting Abstracts, vol. 106, no. 11, abstract 3388, 2005.

[70] M. Staudinger, P. Glorius, and C. Kellner, “Targeted immunotoxin HM1.24-ETA' efficiently eliminates malignant plasma cells in vitro and in vivo," in ASH Annual Meeting Abstracts, vol. 120, p. 1838, 2012.

[71] A. Jalili, S. Ozaki, T. Hara et al., "Induction of HM1.24 peptidespecific cytotoxic $\mathrm{T}$ lymphocytes by using peripheral-blood stem-cell harvests in patients with multiple myeloma," Blood, vol. 106, no. 10, pp. 3538-3545, 2005.

[72] M. Hundemer, S. Schmidt, M. Condomines et al., "Identification of a new HLA-A2-restricted T-cell epitope within HM1.24 as immunotherapy target for multiple myeloma," Experimental Hematology, vol. 34, no. 4, pp. 486-496, 2006.

[73] O. Christensen, A. Lupu, S. Schmidt et al., "Melan-A/MART1 analog peptide triggers anti-myeloma T-cells through crossreactivity with HM1.24," Journal of Immunotherapy, vol. 32, no. 6, pp. 613-621, 2009.
[74] G. Görgün, E. Calabrese, E. Soydan et al., "Immunomodulatory effects of lenalidomide and pomalidomide on interaction of tumor and bone marrow accessory cells in multiple myeloma," Blood, vol. 116, no. 17, pp. 3227-3237, 2010.

[75] B. Neuber, I. Herth, C. Tolliver et al., "Lenalidomide enhances antigen-specific activity and decreases CD45RA expression of T cells from patients with multiple myeloma," Journal of Immunology, vol. 187, no. 2, pp. 1047-1056, 2011.

[76] I. Herth, M. Witzens-Harig, P. Beckhove et al., “Thalidomide maintenance therapy maturates the $\mathrm{T}$ cell compartment and compromises antigen-specific antitumor immunity in patients with multiple myeloma," Experimental Hematology, vol. 41, no. 3, pp. 231-240, 2013.

[77] K. Tarte, Z. Y. Lu, G. Fiol, E. Legouffe, J. Rossi, and B. Klein, "Generation of virtually pure and potentially proliferating dendritic cells from non-CD34 apheresis cells from patients with multiple myeloma," Blood, vol. 90, no. 9, pp. 3482-3495, 1997. 


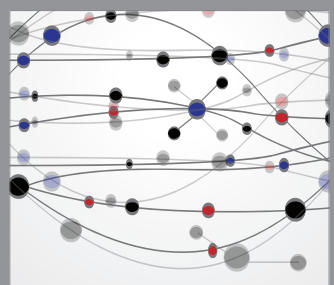

The Scientific World Journal
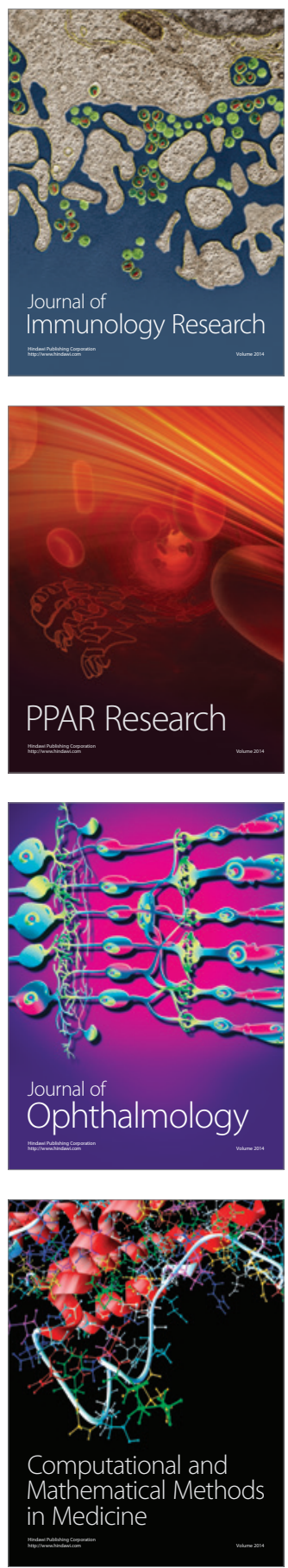

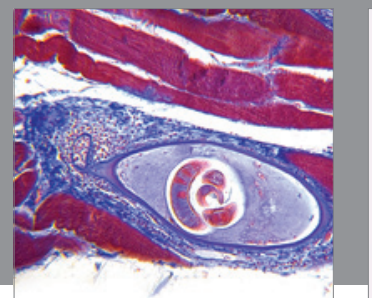

Gastroenterology

Research and Practice
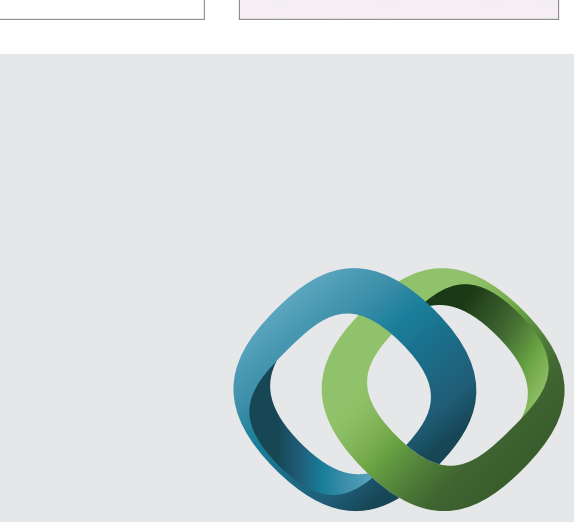

\section{Hindawi}

Submit your manuscripts at

http://www.hindawi.com
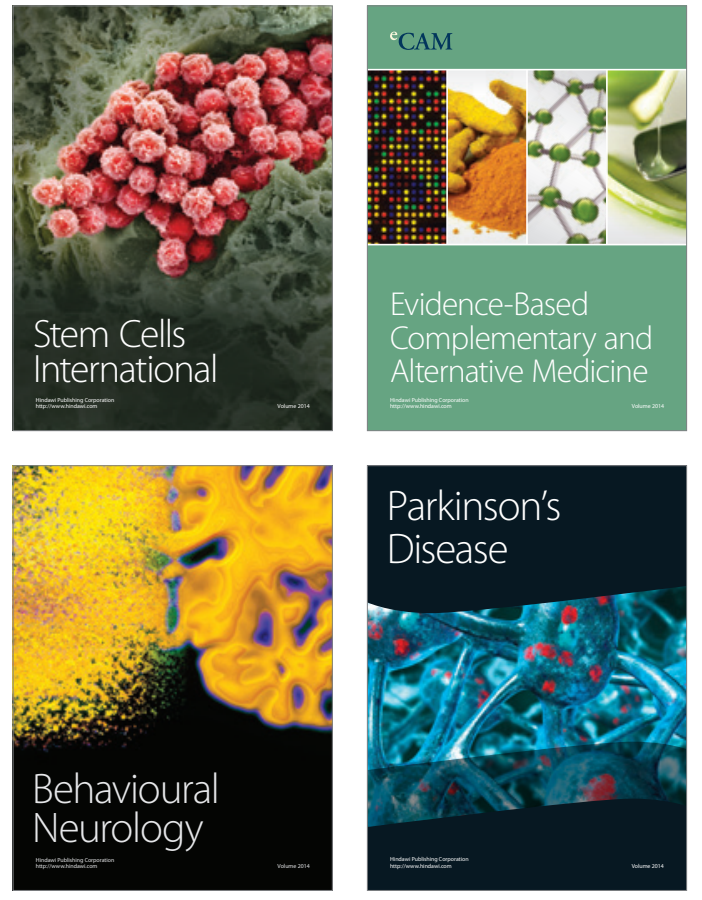
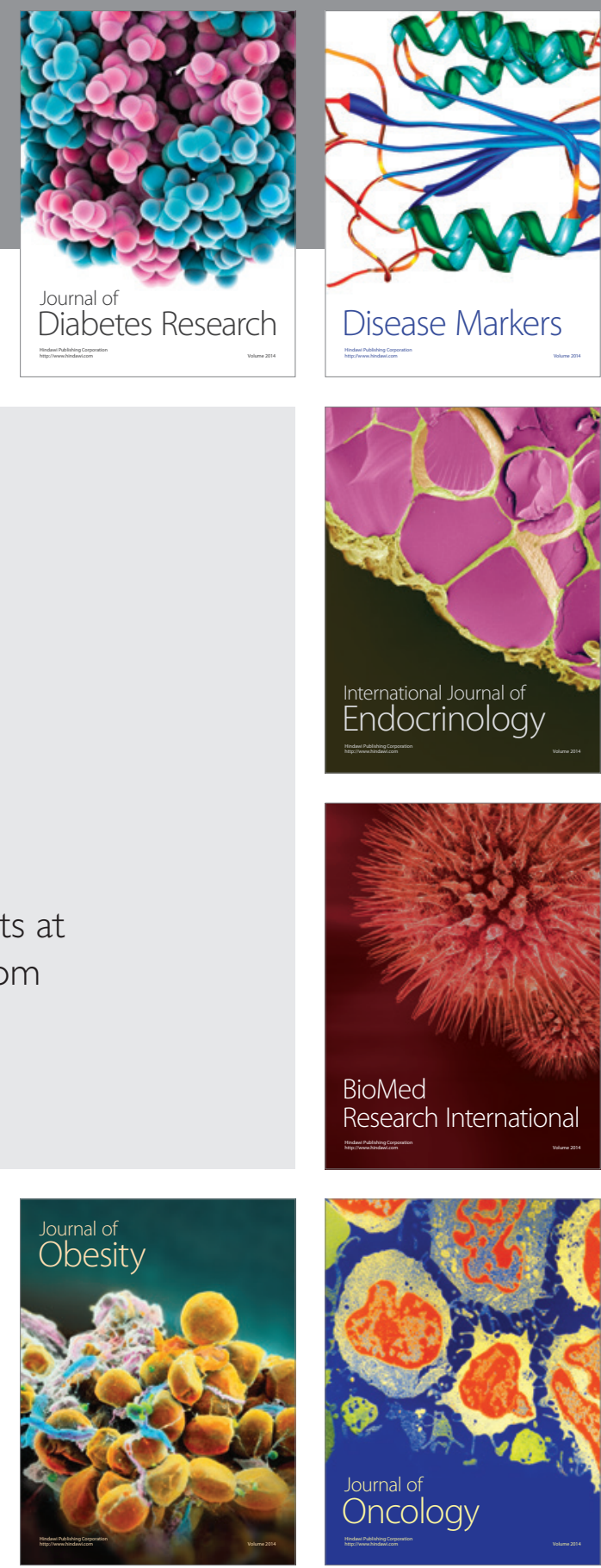

Disease Markers
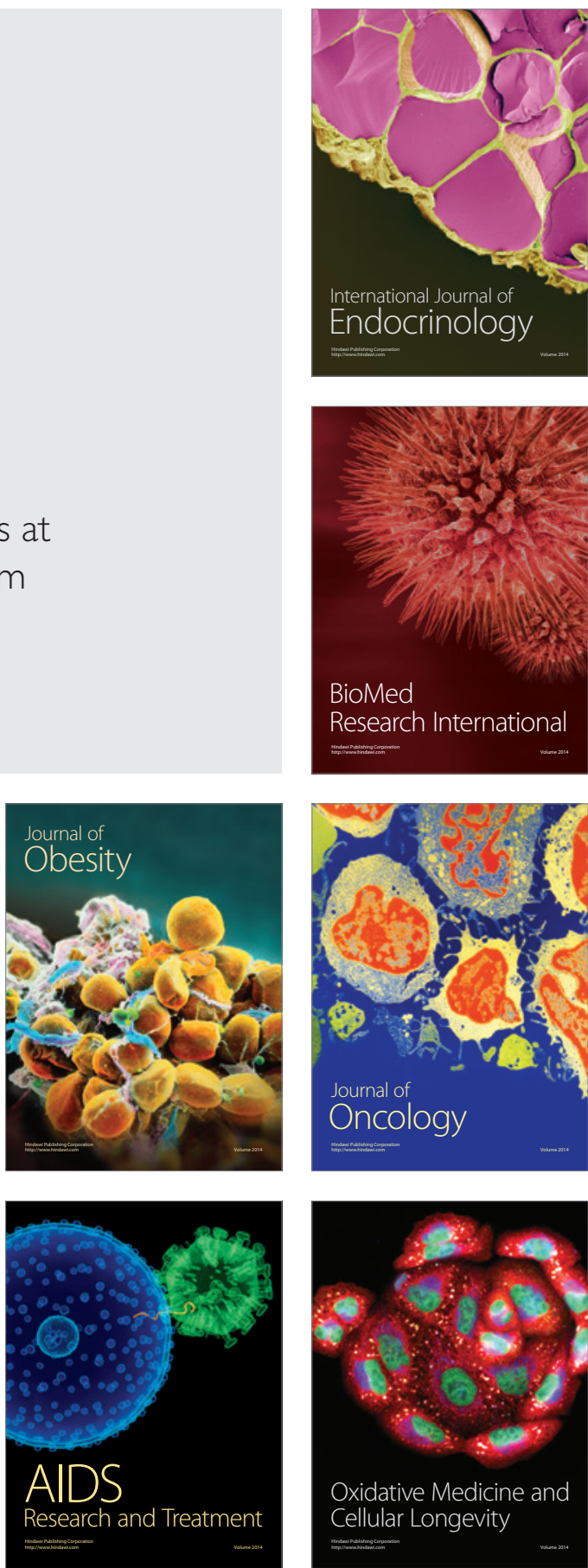